Article

\title{
A New Method Based on PROMETHEE and TODIM for Multi-Attribute Decision-Making with Single-Valued Neutrosophic Sets
}

\author{
Dongsheng $\mathrm{Xu}^{1}{ }^{1}$, Xiaolan Wei ${ }^{1}{ }^{(\mathbb{C}, \text { Hui Ding }}{ }^{2, *}$ and Hongqiong Bin ${ }^{3}$ \\ 1 School of Science, Southwest Petroleum University, Chengdu 610500, China; \\ xudongsheng1976@163.com (D.X.); weixiaolan9767@163.com (X.W.) \\ 2 Department of Mathematical Sciences, The University of Texas at Dallas, 800 West Campbell Road, \\ Richardson, TX 75080, USA \\ 3 School of Foreign Languages, Sichuan University, Chengdu 610065, China; binhongqiong@163.com \\ * Correspondence: Hui.Ding@utdallas.edu
}

Received: 18 September 2020; Accepted: 13 October 2020; Published: 16 October 2020

\begin{abstract}
Single-valued neutrosophic sets (SVNSs) can effectively describe the multi-attribute decision-making (MADM) problems which are characterized by incompleteness and uncertainty. Aiming at the MADM problem of SVNSs, a series of methods are proposed to solve the problem, such as the TODIM and PROMETHEE methods. The main idea of the TODIM method is to establish a relative superiority function of scheme relative to other schemes based on the value function of prospect theory, and the ranking of alternatives is determined according to the obtained superiority. In the PROMETHEE method, the decision maker selects the preference function for each attribute according to their preference, and then calculates the priority index, inflow, outflow and net flow according to the difference of the attribute values of scheme, so as to determine the ranking of alternatives. In this paper, a new method based on PROMETHEE and TODIM is proposed to solve the MADM problem under the single-valued neutrosophic environment. Based on the calculation formula of inflow and outflow in PROMETHEE method, and the calculation formula of overall dominance in the TODIM method, a new integrated formula is obtained.
\end{abstract}

Keywords: multi-attribute decision-making; TODIM; PROMETHEE; single-valued neutrosophic sets

\section{Introduction}

In real life, most decision-making problems involve multiple schemes and multiple attributes, which are called multi-attribute decision-making (MADM) problems. How to sort and select the alternatives under given conditions is the key to solve this problem. In traditional MADM methods, alternatives are evaluated with crisp values generally. However, due to the complexity of objective things and the subjectivity of humans, MADM problems are often accompanied by uncertainty, so the decision information given is often fuzzy or linguistic. In order to describe fuzzy concepts, Zadeh [1] proposed the concept of the fuzzy set (FS) and obtained in-depth research. The FS is a tool to express fuzzy information. On this basis, Atanassov [2] defined the intuitionistic fuzzy set by adding a parameter, that is, non-membership degree. Intuitionistic fuzzy sets consider both membership degree and non-membership degree. Although FS theory has been widely developed and popularized, it cannot handle all types of uncertainties in real life, such as uncertain and inconsistent information. Therefore, Smarandache [3] proposed the concept of a neutrosophic set. The neutrosophic set is an extension of the intuitionistic fuzzy set, which contains a truth-membership function, an indeterminacy-membership function, and a falsity-membership function. After that, some scholars 
successively proposed single-valued neutrosophic sets (SVNSs), multi-valued neutrosophic sets (MVNSs) and interval neutrosophic sets (INSs). This article takes the SVNSs as an example.

For the MADM problems, a series of decision-making methods have been developed, such as PROMETHEE [4], TOPSIS [5], TODIM [6,7], VIKOR [8], ELECTRE [9], etc. [10]. This paper mainly introduces the TODIM and PROMETHEE methods. In recent years, the TODIM method has been well developed and applied in various fields-for example, Wang and Li [11] extended TODIM method to MVNSs; Xu, Wei and Wei [12] extended the TODIM method to SVNSs and INSs. Xiao and Guo [13] proposed a risk ranking method of interval-valued hesitation fuzzy TODIM based on fuzzy theory and multi-attribute decision model. Liu and Teng [14] extended the TODIM method to two-dimensional uncertain linguistic information. In order to solve the multi-criteria decision making (MCDM) problem with unknown weights, Yu and Wang [15] proposed an interactive MCDM approach based on an acronym in Portuguese of an interactive and TODIM method and nonlinear programming (NLP) with intuitionistic linguistic numbers (ILN). Aiming at the problem of intuitionistic language multi-attribute group decision making where there is correlation between attributes, Liu [16] proposed an intuitionistic language TODIM multi-attribute group decision making method based on Choquet integration. Guo and Sun [17] proposed an extended TODIM under single-valued neutrosophic linguistic environment. Lin, Wang and $\mathrm{Xu}$ [18] extended the traditional TODIM method to handle hesitant fuzzy linguistic term sets (HFLTSs) based on novel comparison functions and distance measure. Liu and Teng [19] provided an extended probabilistic linguistic TODIM (PL-TODIM) method. $\mathrm{Xu}$, Hong and Xiang [20] combined subjective weights and objective weights, and used TODIM to solve MADM problems with unknown attribute weights in venture capital. Wang and Liu [21] proposed the intuitionistic linguistic TODIM (IL-TODIM) method and intuitionistic uncertain linguistic TODIM (IUL-TODIM) method to solve uncertain MADM problems with IL and IUL variables. Liu [22] proposed a TODIM decision-making method for the multi-attribute decision making problem of trigonometric intuitionistic fuzzy numbers. Tseng et al. [23] extended TODIM to interval-valued intuitive fuzzy (IVIF) environment. In short, TODIM method has been well developed in all aspects [24-27].

In addition, the PROMETHEE method has been well extended in various fields [28-32]. Sun and Zhu [33] proposed a robustness analysis method for PROMETHEE- II's weights which includes robustness conditions and robustness design process with incomplete information. Zhu, Li and Wang [34] proposed a method of risk assessment based on prospect theory and PROMETHEE. Liang, Wang and Zhang [35] proposed two extended projection-based preference ranking organization methods for enrichment evaluations for MCDM with HFLTSs. Wang [36] proposed a PROMETHEE method with incomplete information. Tian, Liu and Wang [37] improved the PROMETHEE II method based on axiomatic fuzzy sets (AFS). Wan et al. [38] developed a hesitant fuzzy PROMETHEE for multi-criteria group decision-making and applied to green supplier selection. Liu, Cheng and Zhang [39] extended the PROMETHEE method to a probability multi-valued neutrosophic sets (PMVNSs) environment. Sun et al. [40] defined the stability index based on the maximum evaluation deviation of the program evaluation for PROMETHEE-II's weight, and proposed a weight setting method based on linear programming. On the basis of PROMETHEE method, Chen [41] developed a new MCDM method that uses the approach of likelihood-based outranking comparisons within the environment of interval type-2 fuzzy sets. Zhao, Peng and Li [42] proposed an improved PROMETHEE-II method to improve the efficiency and response time in incident management. Yuan and Zhang [43] introduced the normal cloud model into PROMETHEE method. Liu [44] proposed a PROMETHEE multi-attribute decision-making method based on attribute association for decision-making problems with known attribute fuzzy measures and interval hesitant fuzzy sets. Liang et al. [45] adopted the PROMETHEE method to select appropriate hazardous waste disposal enterprises. Gao, Tang and Zhou [46] extended the priority function in PROMETHEE method for group MCDM problems with fuzzy evaluation and incomplete information of criteria's and decision-makers' weights. Liu and Guan [47] adopted the information entropy to determine the objective weight corresponding to each indicator, and used the PROMETHEE-II method to select suppliers. 
It can be seen from the above that the PROMETHEE and TODIM methods are very common in MADM problems. In this paper, we combine PROMETHEE with the TODIM method. In previous research, there have been combinations of the two methods-for example, Peng et al. [48] proposed TOPSIS and TODIM methods based on two-dimensional linguistic variables for the MADM problems with evaluation information as two-dimensional linguistic variables. Arya and Kumar [49] developed an algorithm for picture fuzzy set using TODIM and VIKOR methods. Liu et al. [50] extended the TODIM and TOPSIS methods to the corresponding distance measure under the Fermatean fuzzy linguistic environment.

In the TODIM method, any two alternatives need to be compared and also lead to high computational complexity. In addition, in the PROMETHEE method, the calculation of the inflows and outflow of the alternatives lack persuasiveness and readability. Both of these methods have some shortcomings, and in order to solve these problems, a new method is proposed based on them. This method does not require you to calculate the distance between the alternatives, and it also does not need you to compare any two alternatives, which reduces a huge amount of calculation. In addition, using the overall dominance and overall disadvantage to calculate the inflow and outflow, we can increase the credibility of the alternative ranking. In this paper, firstly, the SVNSs theory, PROMETHEE and TODIM method are introduced; then, a new method based on PROMETHEE and TODIM is proposed. Through a numerical example, the calculation results of the new method are compared with those of the PROMETHEE and TODIM methods. Finally, the conclusion proves the feasibility of the new method.

\section{Preliminaries}

\subsection{Neutrosophic Sets}

Definition 1. Let $X$ be a space of points (objects) with a generic element in $X$ denoted by $x$, aneutrosophic set $A$ in $X$ is characterized by a truth-membership function $T_{A}(x)$, a indeterminacy-membership function $I_{A}(x)$, and a false-membership function $F_{A}(x)$, where $T_{A}(x), I_{A}(x), F_{A}(x): X \rightarrow[0,1]$ and $0 \leq \sup _{A}(x)+\sup _{A}(x)+$ $\sup F_{A}(x) \leq 3$.

Definition 2. Let $X$ be a space of points (objects) with a generic element in $X$ denoted by $x$, the complement of a neutrosophic set $A$ in $X$ is denoted by $A^{C}$ and is defined as $T_{A^{C}}=\left\{1^{+}\right\} \Theta T_{A}(x), I_{A^{C}}=\left\{1^{+}\right\} \Theta I_{A}(x)$, $F_{A^{C}}=\left\{1^{+}\right\} \Theta F_{A}(x)$ for every $x$ in $X$.

Definition 3. Let $X$ be a space of points (objects) with a generic element in $X$ denoted by $x$, a neutrosophic set $A$ is contained in another neutrosophic set $B, A \subseteq B$ if and only if $\inf _{A}(x) \leq \inf T_{B}(x), \sup T_{A}(x) \leq \sup T_{B}(x)$, $\inf _{A}(x) \geq \inf _{B}(x), \sup _{A}(x) \geq \operatorname{supI}_{B}(x), \operatorname{infF}_{A}(x) \geq \operatorname{infF}_{B}(x)$ and $\sup F_{A}(x) \geq \sup F_{B}(x), x \in X$.

\subsection{Single-Valued Neutrosophic Sets}

Definition 4. Let X be a space of points (objects), a single-valued neutrosophic set (SVNS) A in X is characterized as the following:

$$
A=\left\{\left(x, T_{A}(x), I_{A}(x), F_{A}(x)\right) \mid x \in X\right\}
$$

where the truth-membership function $T_{A}(x)$, indeterminacy-membership function $I_{A}(x)$ and false-membership function $F_{A}(x), T_{A}(x): X \rightarrow[0,1], I_{A}(x): X \rightarrow[0,1]$ and $F_{A}(x): X \rightarrow[0,1]$ with the condition $0 \leq T_{A}(x)+I_{A}(x)+F_{A}(x) \leq 3$. That is, an SVNN can be expressed as $A=\left(T_{A}, I_{A}, F_{A}\right)$, $T_{A} \in[0,1], I_{A} \in[0,1], F_{A} \in[0,1]$ and $0 \leq T_{A}+I_{A}+F_{A} \leq 3$.

Definition 5. Let $A$ and B be two single-valued neutrosophic numbers (SVNNs), then the normalized Hamming distance between them is:

$$
d(A, B)=\frac{\left(\left|T_{A}-T_{B}\right|+\left|I_{A}-I_{B}\right|+\left|F_{A}-F_{B}\right|\right)}{3} .
$$


Definition 6. Let $A=\left(T_{A}, I_{A}, F_{A}\right)$ be a $S V N N$, a score function $\mathrm{S}(A)$ is:

$$
S(A)=\frac{\left(2+T_{A}-I_{A}-F_{A}\right)}{3}, S(A) \in[0,1] .
$$

Definition 7. Let $A=\left(T_{A}, I_{A}, F_{A}\right)$ be a $S V N N$, an accuracy function $\mathrm{H}(A)$ is:

$$
\mathrm{H}(A)=T_{A}-F_{A}, \mathrm{H}(A) \in[-1,1] .
$$

where $\mathrm{H}(A)$ is the degree of accuracy of SVNN $A$. The larger the value of $\mathrm{H}(A)$ is, the higher the degree of accuracy of the SVNN $A$.

Definition 8. Let $A$ and $B$ be two SVNNs, If $S(A)<S(B)$, then $A<B$; If $S(A)=S(B)$, then

(1) if $H(A)=H(B)$, then $A=B$;

(2) if $H(A)<H(B)$, then $A<B$.

Definition 9. Let $A=\left(T_{A}, I_{A}, F_{A}\right)$ be a $S V N N$, the complement of $S V N N A$ is:

$$
A^{C}=\left(F_{A}, 1-I_{A}, T_{A}\right)
$$

For the convenience of research, Brans et al. proposed six preference functions, as shown in Table 1. $q, p$ and $s$ are three parameters of the preference function: $q$ is the indifference threshold, $p$ is

\begin{tabular}{|c|c|c|c|c|c|c|c|c|}
\hline \multicolumn{3}{|c|}{ Usual Function } & \multicolumn{3}{|c|}{ V-Shape Function } & \multicolumn{3}{|c|}{ Level Function } \\
\hline$P(d)$ & $\left\{\begin{array}{l}1 \\
0\end{array}\right.$ & $\begin{array}{l}, d>0 \\
d=0\end{array}$ & $P(d)=$ & $=\left\{\begin{array}{l}\frac{d}{q} \\
1\end{array}\right.$ & $\begin{array}{l}>0 \\
=0\end{array}$ & $P(d)=$ & $\begin{array}{c}0 \\
0.5 \\
1\end{array}$ & $\begin{array}{c}, d \leq q \\
, q<d \leq p \\
, d>p\end{array}$ \\
\hline \multicolumn{3}{|c|}{ Liner Function } & \multicolumn{3}{|c|}{ Gauss Function } & \multicolumn{3}{|c|}{ U-shape Function } \\
\hline$P(d)=$ & $\begin{array}{c}0 \\
\frac{d-p}{p-q} \\
1\end{array}$ & $\begin{array}{c}, d \leq q \\
, q<d \leq p \\
, d>p\end{array}$ & $P(d)=$ & $\begin{array}{c}1-e^{\frac{d^{2}}{2 s^{2}}} \\
0\end{array}$ & $\begin{array}{l}, d>0 \\
, d \leq 0\end{array}$ & $P(d)=$ & $\begin{array}{l}1 \\
0\end{array}$ & $\begin{array}{c}, d \geq q \\
0 \leq d<q\end{array}$ \\
\hline
\end{tabular}
the absolute preference threshold, and $s$ is a value between $p$ and $q$.

Table 1. Preference functions.

\section{Decision Method}

\subsection{PROMETHEE Method}

Let the alternatives be $A=\left(A_{1}, \ldots, A_{m}\right)$, and the attributes be $G=\left(G_{1}, G_{2}, \ldots, G_{n}\right)$. Let the weights of the attributes be $W=\left(w_{1}, w_{2}, \ldots, w_{n}\right)$, where $0 \leq w_{j} \leq 1, \sum_{j=1}^{n} w_{j}=1$. Let $a_{i j}$, $i=1,2, \ldots, m, j=1,2, \ldots, n$, be the attribute value of the alternative $A_{i}$ with attribute $G_{j}$, the $A=\left(a_{i j}\right)_{m \times n}=\left(\left\langle T_{i j}, I_{i j}, F_{i j}\right\rangle\right)_{m \times n}$ is a SVNNs matrix, where $T_{i j}, I_{i j}$ and $F_{i j}$ are membership degree, indeterminacy-membership degree and non-membership degree. The following is the calculation procedure of PROMETHEE method.

Step 1: Standardize the decision information. That is, normalizing $A=\left(a_{i j}\right)_{m \times n}$ into $B=\left(b_{i j}\right)_{m \times n}$. If the decision is a cost factor, the decision information should be changed by its complementary set, while if it is an efficient factor, it should not be changed. 
Step 2: Construct a preference function $P_{j}\left(B_{i}, B_{r}\right)$ of alternative $B_{i}$ relative to $B_{r}$ under the attribute $G_{j}$ by

$$
P_{j}\left(B_{i}, B_{r}\right)=\left\{\begin{array}{rl}
0 & , d \leq p \\
\frac{d-p}{q-p} & , p<d<q . \\
1 & , d \geq q
\end{array} .\right.
$$

There are 6 typical preference functions in Table 1. Decision makers choose preference functions according to their own preferences. In certain circumstances, decision makers can also construct preference functions by themselves. $d$ is the priority function parameter and the difference between the criterion values of scheme $B_{i}$ and $B_{r}$.

Step 3: We define the priority index $\pi\left(B_{i}, B_{r}\right)$ of the scheme $B_{i}$ relative to $B_{r}$ by

$$
\pi\left(B_{i}, B_{r}\right)=\frac{\sum_{j=1}^{n} w_{j} P_{j}\left(B_{i}, B_{r}\right)}{\sum_{j=1}^{n} w_{j}}=\sum_{j=1}^{n} w_{j} P_{j}\left(B_{i}, B_{r}\right) .
$$

Step 4: Calculate the inflow $\phi^{+}\left(B_{i}\right)$, outflow $\phi^{-}\left(B_{i}\right)$ and net flow $\phi\left(B_{i}\right)$ of the object, as following

$$
\begin{gathered}
\phi^{+}\left(B_{i}\right)=\sum_{r=1}^{n} \pi\left(B_{i}, B_{r}\right)=\sum_{r=1}^{n} \sum_{j=1}^{m} w_{j} P_{j}\left(d_{i r}\right) \\
\phi^{-}\left(B_{i}\right)=\sum_{r=1}^{n} \pi\left(B_{r}, B_{i}\right)=\sum_{r=1}^{n} \sum_{j=1}^{m} w_{j} P_{j}\left(d_{r i}\right) \\
\phi\left(B_{i}\right)=\phi^{+}\left(B_{i}\right)-\phi^{-}\left(B_{i}\right)
\end{gathered}
$$

where $\phi^{+}\left(B_{i}\right)$ indicates the degree to which scheme $B_{i}$ exceeds other schemes, and $\phi^{-}\left(B_{i}\right)$ indicates the degree to which it is exceeded.

Step 5: Rank the alternatives according to the net flow value of the object. If $\phi\left(B_{i}\right)>\phi\left(B_{r}\right), B_{i}$ is higher than $B_{r} ;$ if $\phi\left(B_{i}\right)<\phi\left(B_{r}\right), B_{r}$ is higher than $B_{i} ;$ If $\phi\left(B_{i}\right)=\phi\left(B_{r}\right)$, that means there is no difference between $B_{i}$ and $B_{r}$.

\subsection{TODIM Method}

The TODIM method [51,52] describes the dominance of each alternative over others by constructing a function of multi-attribute values. The MADM problem is given with single-valued neutrosophic information.

This question is the same as that in Section 3.1, where $A$ and $G$ are constant. The following is the calculation procedure of TODIM method.

Step 1: Standardize the decision information. That is, normalizing $A=\left(a_{i j}\right)_{m \times n}$ into $B=\left(b_{i j}\right)_{m \times n}$. If the decision is a cost factor, the decision information should be changed by its complementary set, while an efficient factor, it should not be changed.

Step 2: Calculate $w_{j r}$, which is the relative weight of $G_{j}$ to $G_{r}$, where

$$
w_{j r}=\frac{w_{j}}{w_{r}}(j, r=1,2, \ldots, n)
$$

where $w_{j}$ is the weight of the attribute of $G_{j}$ and $w_{r}=\max \left\{w_{j} \mid j=1,2, \ldots, n\right\}$. There are many methods to determine the weight [53], and the subjective assigned method is used here. 
Step 3: Find out the dominance degree of $B_{i}$ over every alternative $B_{t}$ by $\sigma\left(B_{i}, B_{t}\right)=$ $\sum_{j=1}^{n} \varphi_{j}\left(B_{i}, B_{t}\right)(i=1,2, \ldots, m)$, where

$$
\varphi_{j}\left(B_{i}, B_{t}\right)=\left\{\begin{array}{cc}
\sqrt{\frac{w_{j r} d\left(b_{i j}, b_{t j}\right)}{\sum_{j=1}^{n} w_{j r}}}, & \text { if } b_{i j}>b_{t j} \\
0, & \text { if } b_{i j}=b_{t j} \\
-\frac{1}{\theta} \sqrt{\frac{\left(\sum_{j=1}^{n} w_{j r}\right) d\left(b_{t j}, b_{i j}\right)}{w_{j r}}}, & \text { if } b_{i j}<b_{t j}
\end{array}\right.
$$

where the parameter $\theta$ is the attenuation factor of the losses, and $d\left(b_{i j}, b_{t j}\right)$ is the distance between the SVNNs $b_{i}$ and $b_{t}$ under $G_{j}$. If $b_{i j}>b_{t j}, \varphi_{j}\left(B_{i}, B_{t}\right)$ represents a gain; if $b_{i j}<b_{t j}, \varphi_{j}\left(B_{i}, B_{t}\right)$ shows a loss.

Step 4: Work out the overall dominance of $B_{i}$ by the following function

$$
\xi_{i}=\frac{\sum_{t=1}^{m} \sigma\left(B_{i}, B_{t}\right)-\min _{1 \leq i \leq m}\left\{\sum_{t=1}^{m} \sigma\left(B_{i}, B_{t}\right)\right\}}{\max _{1 \leq i \leq m}\left\{\sum_{t=1}^{m} \sigma\left(B_{i}, B_{t}\right)\right\}-\min _{1 \leq i \leq m}\left\{\sum_{t=1}^{m} \sigma\left(B_{i}, B_{t}\right)\right\}}
$$

Step 5: Rank all alternatives according to the value of $\xi_{i}$. The greater the value of $\xi_{i}$, the better the alternative is.

\section{A New Method Based on PROMETHEE and TODIM}

This question is the same as that in Section 3.1, where $A$ and $G$ are constant. The following is the calculation procedure of new method.

Step 1: Standardize the decision information. That is, normalizing $A=\left(a_{i j}\right)_{m \times n}$ into $B=\left(b_{i j}\right)_{m \times n}$. If the decision is a cost factor, the decision information should be changed by its complementary set, while an efficient factor, it should not be changed. $G_{j}$ by

Step 2: Construct a preference function $P_{j}\left(B_{i}, B_{r}\right)$ of scheme $B_{i}$ relative to $B_{r}$ under the attribute

$$
P_{j}\left(B_{i}, B_{r}\right)=\left\{\begin{aligned}
0 & , d \leq p \\
\frac{d-p}{q-p} & , p<d<q \\
1 & , d \geq q
\end{aligned}\right.
$$

There are 6 typical preference functions, and decision makers choose preference functions according to their own preferences. In certain circumstances, decision makers can also construct preference functions by themselves. The value of the preference function is from 0 to 1 ; the smaller the function value, the smaller the difference between $B_{i}$ and $B_{r}$; when the function value is 0 , there is no difference between $B_{i}$ and $B_{r}$. The closer the value is to 1 , the higher the degree of $B_{i}$ being better than $B_{r}$ is, and when the function value is $1, B_{i}$ is strictly better than $B_{r} . d$ is the priority function parameter and the difference between the criterion values of scheme $B_{i}$ and $B_{r}$. Here, the score function value is used to calculate the criterion value of the scheme.

Step 3: Calculate $w_{j r}$, which is the relative weight of $G_{j}$ to $G_{r}$, where

$$
w_{j r}=\frac{w_{j}}{w_{r}}(j, r=1,2, \ldots, n)
$$

where $w_{j}$ is the weight of the attribute of $G_{j}$ and $w_{r}=\max \left\{w_{j} \mid j=1,2, \ldots, n\right\}$.

Step 4: We define the priority index $\pi\left(B_{i}, B_{r}\right)$ of the scheme $B_{i}$ relative to $B_{r}$ by

$$
\pi\left(B_{i}, B_{r}\right)=\frac{\sum_{j=1}^{n} w_{j r} P_{j}\left(B_{i}, B_{r}\right)}{\sum_{j=1}^{n} w_{j r}}
$$


Step 5: Calculate the inflow $\phi^{+}\left(B_{i}\right)$, outflow $\phi^{-}\left(B_{i}\right)$ and net flow $\phi\left(B_{i}\right)$ of the object, as follows

$$
\begin{gathered}
\phi^{+}\left(B_{i}\right)=\frac{\sum_{r=1}^{m} \pi\left(B_{i}, B_{r}\right)-\min _{1 \leq i \leq m}\left\{\sum_{r=1}^{m} \pi\left(B_{i}, B_{r}\right)\right\}}{\max _{1 \leq i \leq m}\left\{\sum_{r=1}^{m} \pi\left(B_{i}, B_{r}\right)\right\}-\min _{1 \leq i \leq m}\left\{\sum_{r=1}^{m} \pi\left(B_{i}, B_{r}\right)\right\}} \\
\phi^{-}\left(B_{i}\right)=\frac{\sum_{r=1}^{m} \pi\left(B_{r}, B_{i}\right)-\min _{1 \leq i \leq m}\left\{\sum_{r=1}^{m} \pi\left(B_{r}, B_{i}\right)\right\}}{\max _{1 \leq i \leq m}\left\{\sum_{r=1}^{m} \pi\left(B_{r}, B_{i}\right)\right\}-\min _{1 \leq i \leq m}\left\{\sum_{r=1}^{m} \pi\left(B_{r}, B_{i}\right)\right\}} \\
\phi\left(B_{i}\right)=\phi^{+}\left(B_{i}\right)-\phi^{-}\left(B_{i}\right)
\end{gathered}
$$

Step 6: Rank all alternatives according to the value of $\phi\left(B_{i}\right)$. The larger the value of $\phi\left(B_{i}\right)$, the better the alternative is.

\section{Numerical Example and Comparative Analysis}

\subsection{Numerical Example}

We give an example to illustrate the feasibility and rationality of the proposed method. Suppose there are four enterprises $A=\left(A_{1}, A_{2}, A_{3}, A_{4}\right)$ and four attributes $G=\left(G_{1}, G_{2}, G_{3}, G_{4}\right)$. Here, the decision information is given in the form of single-valued neutrosophic number. Suppose $a_{i j}$ is given for the alternative $A_{i}$ under the attribute $G_{j}, i=1,2,3,4$ and $j=1,2,3,4$. The first attribute is the cost factor, and the next three are efficient factors. The weight of each attribute is given by $w=\{0.3,0.2,0.1,0.4\}$. Now we need to select the better one from the four enterprises. The evaluation results of the scheme are given by experts, as shown in the following matrix.



Attribute $G_{1}$ is the cost factor, and the next three, $G_{2}, G_{3}, G_{4}$, are efficient factors. Therefore, the standardized decision matrix shows in the following.

$$
\begin{gathered}
G_{1} \\
B_{1}
\end{gathered}=\begin{array}{cccc}
(0.2,0.2,0.5) & (0.3,0.7,0.1) & (0.6,0.2,0.3) & (0.1,0.2,0.8) \\
B_{2} \\
B_{3} \\
B_{4}
\end{array}\left[\begin{array}{cccc}
(0.2,0.6,0.7) & (0.5,0.1,0.3) & (0.6,0.3,0.6) & (0.7,0.6,0.1) \\
(0.3,0.6,06) & (0.4,0.1,0.8) & (0.5,0.3,0.7) & (0.7,0.3,0.3) \\
(0.1,0.7,0.8) & (0.6,0.5,0.5) & (0.7,0.1,0.2) & (0.5,0.1,0.8)
\end{array}\right]
$$

Then, the preference degree matrix $P_{j}\left(B_{i}, B_{r}\right)$ with respect to $G_{j}$ can be calculated by liner function in Table 1 (suppose $q=1, p=0$ ):

$$
P_{1}=\begin{gathered}
B_{1} \\
B_{1} \\
B_{2} \\
B_{3} \\
B_{4}
\end{gathered}\left[\begin{array}{cccc}
0.0000 & 0.2000 & 0.1333 & 0.3000 \\
0.0000 & 0.0000 & 0.0000 & 0.1000 \\
0.0000 & 0.0667 & 0.0000 & 0.1667 \\
0.0000 & 0.0000 & 0.0000 & 0.0000
\end{array}\right]
$$




$$
\begin{aligned}
& P_{2}=\begin{array}{c}
B_{1} \\
B_{1} \\
B_{2} \\
B_{3} \\
B_{4}
\end{array}\left[\begin{array}{cccc}
0.0000 & 0.0000 & 0.0000 & 0.0000 \\
0.2000 & 0.0000 & 0.2000 & 0.1667 \\
0.0000 & 0.0000 & 0.0000 & 0.0000 \\
0.0333 & 0.0000 & 0.0333 & 0.0000
\end{array}\right]
\end{aligned}
$$



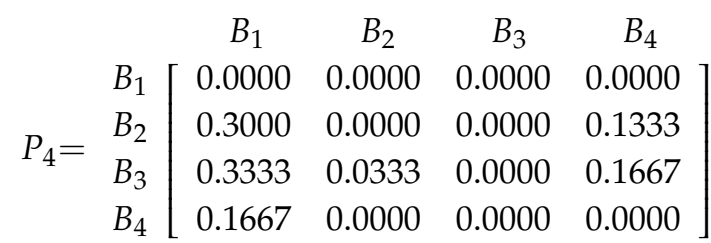

Since $w_{4}=\max \left\{w_{1}, w_{2}, w_{3}, w_{4}\right\}$, the reference attribute's weight is $w_{r}=0.4$. Then, we can calculate the relative weights of the attributes as $w_{1 r}=0.75, w_{2 r}=0.5, w_{3 r}=0.25$ and $w_{4 r}=1$, and the comprehensive priority index of schemes $B_{i}$ and $B_{r}$ is

$$
\pi=\begin{gathered}
B_{1} \\
B_{1} \\
B_{2} \\
B_{3} \\
B_{4}
\end{gathered}\left[\begin{array}{cccc}
0.0000 & 0.0733 & 0.0600 & 0.0900 \\
0.1600 & 0.0000 & 0.0467 & 0.1167 \\
0.1333 & 0.0333 & 0.0000 & 0.1167 \\
0.0833 & 0.0233 & 0.0367 & 0.0000
\end{array}\right]
$$

Next, the inflow, outflow and net flow of each alternative are calculated as Table 2:

Table 2. The inflow, outflow and net flow.

\begin{tabular}{cccc}
\hline Alternative & $\boldsymbol{\phi}^{+}$ & $\boldsymbol{\phi}^{-}$ & $\boldsymbol{\phi}$ \\
\hline$A_{1}$ & 0.4444 & 1.0000 & -0.5556 \\
$A_{2}$ & 1.0000 & 0.0000 & 1.0000 \\
$A_{3}$ & 0.7778 & 0.0541 & 0.7237 \\
$A_{4}$ & 0.0000 & 0.7838 & -0.7838 \\
\hline
\end{tabular}

Finally, we get the net flow value of each alternative $\phi_{1}=-0.5556, \phi_{2}=1.0000, \phi_{3}=0.7237$, $\phi_{4}=-0.7838$, the larger the value of $\phi$, the better the alternative is, thus the most desirable scheme is $A_{2}$.

\subsection{Comparative Analysis}

In order to verify the effectiveness and rationality of the new method, the new method is compared with the PROMETHEE and TODIM based on single-valued neutrosophic sets. The TODIM method fully considers the risk aversion attitude of the decision maker on the basis of the prospect theory, and can adjust the parameters to reflect the risk preference of the decision maker, which is more in line with actual decision-making needs, the parameter $\theta$ is the attenuation factor of the losses.

For the convenience of comparison, the alternatives and weight coefficients are also the same as that in Section 5.1. Next, we discuss the use of TODIM method to sort the alternative under different parameter values. The results are shown in Table 3. 
Table 3. The ranking of the alternative under different parameters $\theta$.

\begin{tabular}{ccc}
\hline $\boldsymbol{\theta}$ & Ranking & Optimal Choice \\
\hline 0.3 & $A_{2}>A_{4}>A_{1}>A_{3}$ & $A_{2}$ \\
0.8 & $A_{2}>A_{4}>A_{1}>A_{3}$ & $A_{2}$ \\
1.0 & $A_{2}>A_{4}>A_{1}>A_{3}$ & $A_{2}$ \\
2.0 & $A_{2}>A_{4}>A_{1}>A_{3}$ & $A_{2}$ \\
2.5 & $A_{2}>A_{4}>A_{1}>A_{3}$ & $A_{2}$ \\
\hline
\end{tabular}

It can be seen from Table 3 that the ranking of the alternative is unchanged as the $\theta$ value changes. In the new method, we continue to discuss the changes of the values of the parameters $p$ and $q$ to the results and compared the results as shown in Table 4.

Table 4. The ranking of the alternative under different parameters $p, q$.

\begin{tabular}{ccc}
\hline$p, q$ & Ranking & Optimal Choice \\
\hline$p=0.0, q=0.1$ & $A_{2}>A_{3}>A_{1}>A_{4}$ & $A_{2}$ \\
$p=0.0, q=0.2$ & $A_{2}>A_{3}>A_{1}>A_{4}$ & $A_{2}$ \\
$p=0.0, q=0.3$ & $A_{2}>A_{3}>A_{1}>A_{4}$ & $A_{2}$ \\
$p=0.0, q=1.0$ & $A_{2}>A_{3}>A_{1}>A_{4}$ & $A_{2}$ \\
$p=0.1, q=0.3$ & $A_{2}>A_{3}>A_{1}>A_{4}$ & $A_{2}$ \\
\hline
\end{tabular}

It can be seen from Table 4 that reasonable selection of parameters $p$ and $q$ has no effect on the results.

Due to how the parameter value changes, the result is consistent; usually, the value of $\theta$ is taken as 2.5, and the value of $p$ and $q$ are taken as 0 and 1 respectively. Suppose $\theta=2.5, p=0, q=1$ and then the comparison results of the three methods are as Table 5:

Table 5. Ranking of methods.

\begin{tabular}{ccc}
\hline Method & Ranking & Optimal Choice \\
\hline TODIM & $A_{2}>A_{4}>A_{1}>A_{3}$ & $A_{2}$ \\
PROMETHEE & $A_{2}>A_{3}>A_{1}>A_{4}$ & $A_{2}$ \\
New method & $A_{2}>A_{3}>A_{1}>A_{4}$ & $A_{2}$ \\
\hline
\end{tabular}

From the above analysis, through the calculation of the same example, similar sorting results are obtained, and the optimal scheme is $A_{2}$. The new method is proposed based on the calculation formula of inflow and outflow in the PROMETHEE method and the calculation formula of overall dominance in the TODIM method. The TODIM method can reasonably depict the decision maker's behaviors under risk. The main reason for the difference is that the new method and the PROMETHEE method depend on the selection of input parameters and preference functions. Although the three methods' ranking results are slightly different, each of the three methods has its own advantages. This proves that the new method proposed is reasonable and effective.

\section{Conclusions}

The single-valued neutrosophic sets (SVNSs) are useful tools to depict the uncertainty of the MADM. In this paper, a new decision-making method based on PROMETHEE and TODIM is proposed for MADM problems. In the new method, based on the calculation formula of inflow and outflow in PROMETHEE method, and the calculation formula of overall dominance in the TODIM method, a new integrated formula is obtained. It does not require you to calculate the distance between the alternatives, and it also does not need you to compare any two alternatives, which reduces the amount of calculation by a huge degree. In addition, using the overall dominance and overall disadvantage to 
calculate the inflow and outflow, we can increase the credibility of the alternative ranking. Due to the complexity of objective things and human subjectivity, MADM problems are often uncertain, so the decision information often given is unclear. Therefore, this method is more applicable when the information in MADM problems in real life is unclear or there is a large amount of data. Finally, a numerical example is given under the background of SVNSs, and the results are compared with the PROMETHEE and TODIM methods to verify the effectiveness and practicability of the new method, which improves and enriches the theory of MADM.

Author Contributions: Methodology, X.W.; editing, H.D.; writing—review and editing, D.X.; formal analysis, H.B.; writing - original draft preparation, X.W. All the authors have read and agreed to the published version of the manuscript.

Funding: The research was funded by the Humanities and Social Sciences Foundation of the Ministry of Education of the People's Republic of China (17YJA630115).

Conflicts of Interest: The authors have no conflict of interest.

\section{References}

1. Zadeh, L.A. Fuzzy sets. Inf. Control. 1965, 8, 338-353. [CrossRef]

2. Atanassov, K. Intuitionistic fuzzy sets. Int. J. Bioautomation 2016, 20, 87-96.

3. Smarandache, F. A unifying field in logics: Neutrosophic logic. In Philosophy; American Research Press: Champaign, IL, USA, 1999; Volume 8, pp. 489-503.

4. Nassereddine, M.; Azar, A.; Rajabzadeh, A.; Afsar, A. Decision making application in collaborative emergency response: A new PROMETHEE preference function. Int. J. Disaster Risk Reduct. 2019, 38, 2212-4209. [CrossRef]

5. Selvachandran, G.; Quek, S.G.; Smarandache, F.; Broumi, S. An extended technique for order preference by similarity to an ideal solution (topsis) with maximizing deviation method based on integrated weight measure for single-valued neutrosophic sets. Symmetry 2018, 10, 236. [CrossRef]

6. Sen, D.K.; Datta, S.; Mahapatra, S.S. Extension of TODIM for decision making in fuzzy environment: A case empirical research on selection of industrial robot. Int. J. Serv. Oper. Manag. 2017, 26, 238-276. [CrossRef]

7. Lee, Y.S.; Shih, H.S. Incremental analysis for generalized TODIM. Cent. Eur. J. Oper. Res. 2016, 24, 901-922. [CrossRef]

8. Arar, T.; Lan, S.K.; Dirik, C. Office location selection by fuzzy AHP and VIKOR. Int. J. Inf. Decis. Sci. 2019, 11, 36-54. [CrossRef]

9. Singh, S.; Verma, K.; Tiwari, K. A novel approach for finding crucial node using ELECTRE method. Int. J. Mod. Phys. B 2020, 34, 217-979. [CrossRef]

10. Stanujkic, D.; Zavadskas, E.K.; Smarandache, F.; Brauers, W.K.; Karabasevic, D. A neutrosophic extension of the MULTIMOORA method. Informatica 2017, 28, 181-192. [CrossRef]

11. Wang, J.Q.; Li, X.E. TODIM method based on multi-valued Neutrosophic set. Control. Decis. 2015, 6, $1139-1142$.

12. Xu, D.S.; Wei, C.; Wei, G.W. TODIM Method for single-valued neutrosophic multiple attribute decision making. Information 2017, 8, 125. [CrossRef]

13. Xiao, C.X.; Guo, J. Improved risk assessment method based on interval hesitation fuzzy TODIM. Comput. Sci. 2020, 47, 225-229.

14. Liu, P.D.; Teng, F. An extended TODIM method for multiple attribute group decision-making based on 2-dimension uncertain linguistic Variable. Complexity 2016, 21, 20-30. [CrossRef]

15. Yu, S.M.; Wang, J.; Wang, J.Q. An extended TODIM approach with intuitionistic linguistic numbers. Int. Trans. Oper. Res. 2018, 25, 781-805. [CrossRef]

16. Liu, N.Y. Intuitive linguistic TODIM multi-attribute group decision-making method based on Choquet integral. Math. Pract. Underst. 2020, 50, 10-19.

17. Guo, Z.X.; Sun, F.F. TODIM decision-making method under single-valued Neutrosophic linguistic environment. J. Hebei Univ. 2019, 39, 561-567.

18. Lin, M.W.; Wang, H.B.; Xu, Z.S. TODIM-based multi-criteria decision-making method with hesitant fuzzy linguistic term sets. Artif. Intell. Rev. 2019, 53, 1-15. [CrossRef] 
19. Liu, P.D.; Teng, F. Probabilistic linguistic TODIM method for selecting products through online product reviews. Inf. Sci. 2019, 485, 441-455. [CrossRef]

20. Xu, D.; Hong, Y.; Xiang, K. A method of determining multi-attribute weights based on single-valued neutrosophic numbers and its application in TODIM. Symmetry 2019, 11, 506. [CrossRef]

21. Wang, S.; Liu, J. Extension of the TODIM method to intuitionistic linguistic multiple attribute decision making. Symmetry 2017, 9, 95. [CrossRef]

22. Liu, N.Y. Triangular intuitionistic fuzzy number multi-attribute decision-making method considering the psychological behavior of decision makers. J. Lanzhou Univ. Arts Sci. 2018, 32, 1-7.

23. Tseng, M.L.; Lin, Y.H.; Tan, K.H.; Chen, R.H.; Chen, Y.H. Using TODIM to evaluate green supply chain practices under uncertainty. Appl. Math. Model. 2014, 38, 2983-2995. [CrossRef]

24. Gai, L.; Peng, Z.Y.; Zhang, J.M.; Zhang, J.F. Emergency medical center location problem with people evacuation solved by extended TODIM and objective programming. J. Comb. Optim. 2019, 4, 1-26. [CrossRef]

25. Ren, H.P.; Liu, M.F.; Zhou, H. Extended TODIM Method for MADM problem under trapezoidal intuitionistic fuzzy environment. Int. J. Comput. Commun. Control. 2019, 14, 220-232. [CrossRef]

26. Krohling, A.R.; Pacheco, A.G.C. Interval-valued intuitionistic fuzzy TODIM. Procedia Comput. Sci. 2014, 31, 236-244. [CrossRef]

27. Tian, X.L.; Xu, Z.S.; Gu, J. An extended TODIM based on cumulative prospect theory and its application in venture capital. Informatica 2019, 30, 413-429. [CrossRef]

28. Liu, N.Y. Intuitionistic linguistic multi-attribute group decision making method based on PROMETHEE method. Stat. Decis. Mak. 2019, 35, 9-53.

29. Feng, F.; Xu, Z.S.; Fujita, H.; Liang, M.Q. Enhancing PROMETHEE method with intuitionistic fuzzy soft sets. Int. J. Intell. Syst. 2020, 35, 1071-1104. [CrossRef]

30. Feng, Q.Q.; Tan, Q.Y.; Zhang, H.R. Hesitant fuzzy PROMETHEE method based on possibility degree. Sci. Technol. Guide 2015, 33, 90-93.

31. Qi, X.L.; Yu, X.H.; Wang, L.; Liao, X.L.; Zhang, S.J. PROMETHEE for prioritized criteria. Soft Comput. 2019, 23, 11419-11432. [CrossRef]

32. Zhao, J.B.; Zhu, H.; Li, H. 2-Dimension linguistic PROMETHEE methods for multiple attribute decision making. Expert Syst. Appl. 2019, 127, 97-108. [CrossRef]

33. Sun, S.Y.; Zhu, H.M. PROMETHEE priority function selection and parameter configuration method. Syst. Eng. Electron. Technol. 2017, 39, 120-124.

34. Zhu, J.H.; Li, Y.L.; Wang, R. FMEA risk assessment based on prospect theory and PROMETHEE. Oper. Res. Manag. 2018, 27, 147-157.

35. Liang, R.X.; Wang, J.Q.; Zhang, H.Y. Projection-based PROMETHEE methods based on hesitant fuzzy linguistic term sets. Int. J. Fuzzy Syst. 2018, 20, 2161-2174. [CrossRef]

36. Wang, J.Q. PROMETHEE method and its application with incomplete information. Syst. Eng. Electron. Technol. 2019, 11, 95-99.

37. Tian, X.J.; Liu, X.D.; Wang, L.D. An improved PROMETHEE II method based on axiomatic fuzzy sets. Neural Comput. Appl. 2014, 25, 1675-1683. [CrossRef]

38. Wan, S.P.; Zou, W.C.; Zhong, L.J.; Dong, J.Y. Some new information measures for hesitant fuzzy PROMETHEE method and application to green supplier selection. Soft Comput. 2019, 24, 1-25. [CrossRef]

39. Liu, P.D.; Cheng, S.F.; Zhang, Y.M. An extended multi-criteria group decision-making promethee method based on probability multi-valued neutrosophic sets. Int. J. Fuzzy Syst. 2019, 21, 2472-2489. [CrossRef]

40. Sun, S.Y.; Qiu, Z.M.; Liu, Z.; Wang, H.Y. PROMETHEE weight setting method based on maximizing dispersion. In Proceedings of the 8th China Youth Operational Information Management Scholars Conference, Guilin, China, 18 August 2006.

41. Chen, T.Y. An interval type-2 fuzzy PROMETHEE method using a likelihood-based outranking comparison approach. Inf. Fusion 2015, 25, 105-120. [CrossRef]

42. Zhao, H.J.; Peng, Y.; Li, W. Revised PROMETHEE II for improving efficiency in emergency response. Procedia Comput. Sci. 2013, 17, 181-188. [CrossRef]

43. Yuan, X.M.; Zhang, X. PROMETHEE multi criteria decision making method based on cloud model. Fuzzy Syst. Math. 2018, 32, 92-103.

44. Liu, N.Y. Interval hesitant fuzzy PROMETHEE multiple attribute decision making method based on Association. Pract. Underst. Math. 2018, 48, 17-25. 
45. Liang, X.D.; Miao, J.R.; Li, Y.J.; Yang, X.; Li, Z. Hazardous waste disposal enterprise selection in China using hesitant Fuzzy PROMETHEE. Int. J. Environ. Res. Public Health 2020, 17, 12. [CrossRef]

46. Gao, Y.; Tang, X.P.; Zhou, X.H. Group multi-criteria fuzzy programming method based on PROMETHEE. Syst. Eng. Electron. Technol. 2007, 2, 205-208.

47. Liu, P.D.; Guan, Z.L. Supply chain supplier selection based on entropy weight and PROMETHEE method. J. Beijing Jiaotong Univ. 2008, 2, 3-37.

48. Ping, Y.N.; Wu, Q.; Zhou, L.G. Chen Huayou. Fuzzy multiple attribute decision making method based on two-dimensional linguistic evaluation information. Fuzzy Syst. Math. 2018, 32, 155-168.

49. Arya, V.; Kumar, S. A new picture fuzzy information measure based on Shannon entropy with applications in opinion polls using extended VIKOR-TODIM approach. Comput. Appl. Math. 2020, 39, 197. [CrossRef]

50. Liu, D.H.; Liu, Y.Y.; Wang, L.Z. Distance measure for Fermatean fuzzy linguistic term sets based on linguistic scale function: An illustration of the TODIM and TOPSIS methods. Int. J. Intell. Syst. 2019, 34, 2807-2834. [CrossRef]

51. Gomes, L.F.A.M.; Lima, M.M.P.P. TODIM: Basics and application to multicriteria ranking of projects with environmental impacts. Found. Comput. Decis. Sci. 1991, 16, 113-127.

52. Gomes, L.F.A.M.; Lima, M.M.P.P. From modelling individual preferences to multicriteria ranking of discrete alternatives: A look at prospect theory and the additive difference model. Found. Comput. Decis. Sci. 1992, 17, 171-184.

53. Sudha, S.; Gomes, L.F.A.M.; Vijayalakshmi, K.R. Assessment of MCDM problems by TODIM using aggregated weights. Neutrosophic Sets Syst. 2020, 35, 78-98.

Publisher's Note: MDPI stays neutral with regard to jurisdictional claims in published maps and institutional affiliations.

(C) 2020 by the authors. Licensee MDPI, Basel, Switzerland. This article is an open access article distributed under the terms and conditions of the Creative Commons Attribution (CC BY) license (http://creativecommons.org/licenses/by/4.0/). 